$\mathbb{P}$ periodica polytechnica

Civil Engineering

$58 / 1(2014) 55,62$

doi: 10.3311/PPci.7408

http://periodicapolytechnica.org/ci

Creative Commons Attribution (i)

RESEARCH ARTICLE

\section{A Mechanistic-Empirical Approach for Asphalt Overlay Design of Asphalt Pavement Structures}

\author{
István Fi / Ibolya Szentpéteri
}

Received 2013-06-18, revised 2013-10-10, accepted 2013-11-18

\begin{abstract}
Nowadays many overlay design methods are known, which is different from country to country. The current Hungarian overlay design standard goes back several decades, when the laying of a new asphalt layer on the existing pavements meant the overlay of pavement. Because of the spreading of new construction technologies and economics it is necessary to develop methods, which can take into account the characteristics of existing pavement structure after remove of the surface and binder course. This paper deals a suggestion for overlay design, which is based on mechanical-empirical method and developed at Highway Laboratory of BME. The method uses the strain value at the bottom of existing asphalt layer and the equivalent modulus of pavement structures for determination of overlaid binder course.
\end{abstract}

\section{Keywords \\ overlay design $\cdot$ multi-layer pavement $\cdot$ fatigue line $\cdot$ equiva-} lent modulus

\section{Introduction}

In the last couple of years parallel to connection to European Union we created a lot of research work at the Highway Laboratory of Department of Highway and Railway Engineering, BME (Budapest University of Technology and Economics). Helping with the wide range of new testing equipment the Laboratory would be suited to deal deeply with the mechanical analysis of working of loaded pavement constructions. However, using of finite element software is gaining nowadays to design; mechanistic methods are used in many countries for several decades [1]. Different predicting models and applications may also assist during the design method, too. A good example is the use of Monte-Carlo simulation to predict the properties of asphalt mixture, which was carried out at our Department in 2010. [2]

The knowledge of the fatigue resistant of existing layer is important to determine the remaining life of pavement structure. Many researchers are working on developing a model that takes into account the fatigue, rheological or ageing properties of pavement structure. In addition, the difference between the mechanistic, empirical and semi-empirical method is examined [3].

Nowadays, the recycling technologies are preferred more and more often during the overlay design. The asphalt is an almost $100 \%$ recyclable material. Some countries, such as India, not only prescribe the thickness of removing layer but an attempt is made to use reclaimed asphalt for the mix design. [4]. Their research and results were supported with several laboratory tests, e.g. fatigue test and creep test. The application of the rubber grinds produced from tires represents the new direction of the recycling. Although a few investigations were conducted in Hungary, in the U.S. and Europe have been tested the new type of mixture in last years. The fatigue behaviour of recycled tire rubber-filled asphalt was placed in the foreground in Spain, when thinking of the further development of design method. [5]

An Egyptian study published last year dealt with the fatigue life prediction of pavement structure. BISAR software was used for the calculations. [6] Our investigation was started on the basis of the above mentioned considerations. The incompletion of our current standard is unable to handle the recycling tech- 
nologies. This article is a summary of our new investigations, which is a mechanistic - empirical design method. This method recommends that the overlay should be carried out to remove of surface and binder course.

\section{Generally about Overlay Design Methodologies}

Generally three methods can be used for overlay design: the deflection approach, the mechanistic-empirical approach and the effective thickness approach. All three methods are usable, considering the following two important issues: to make a real pavement condition survey and to delineate more homogeneous sections, depending on the traffic load and pavement conditions. If more than one sections are chosen to consider the construction technologies and the total maintenance project costs should be considered. The essentials of above mentioned methods can be summarized as follows.

The defection method was developed on the base of empirical relationship between measuring deflection and overlay thickness [7]. The method starts with deflection measurement of the weaker pavement and subgrade. Following this step depending on the traffic load the required overlay thickness can be estimated, which must be thick enough to reduce the deflection to a tolerable value.

The basic concept of the effective thickness approach means that the required thickness of the overlay will be equal to the difference between the required thickness of a new pavement and the effective thickness of the existing pavement. The effective thickness is in proportion the remaining life of pavement. By using this method, all thicknesses of new and existing materials must be converted into an equivalent thickness of hot mix asphalt layers based on their types and properties.

In the mechanistic-empirical approach first the remaining life of the existing pavement must be evaluated. This method requires the determination of critical stress, strain or deflection in the pavement by some mechanistic methods based on some empirical failure criteria. The most frequently used failure criteria is the fatigue cracking and the permanent deformation. The following procedure usable if the existing pavement has remaining fatigue life, Eq. (1):

$$
\sum_{i=1}^{m} \frac{n_{i}}{N_{i}}<1
$$

Where $n_{i}$ is the number of load repetition in the $i^{\text {th }}$ load group, $N_{i}$ the allowable number of load repetition in the $i^{\text {th }}$ load group and $m$ is the number of load groups.

The fatigue equation worked out by the Asphalt Institute [7] is the following Eq. (2):

$$
N_{f}=0,0796\left(\varepsilon_{t}\right)^{-3,291}\left(E_{s}\right)^{-0,854}
$$

Where $N_{f}$ is the maximum allowable number of load repetitions to control fatigue cracking (fatigue cracking is minimize in $20 \%$ of road surface), and $E_{s}$ is stiffness modulus of the asphalt pavement.
The remaining life of existing pavement is estimated by Eq. (3):

$$
\frac{n_{a r}}{N_{a}}=1-\frac{n_{e}}{N_{a}}
$$

Where $n_{a r}$ is the additional load repetition number of existing pavement after the overlay, $N_{a}$ is the allowable number of load repetition on the existing pavement before overlay, $n_{e}$ is the effective load repetitions on the existing pavement before overlay. According to the above-mentioned method by using Eq. (2) the maximum allowable number of load repetitions on the existing pavement can be calculated (the horizontal tensile strain at the bottom of existing layer and its stiffness modulus is needed). In the second while using Eq. (3) the remaining life of existing pavement can be calculated (where of $n_{e}$ and $N_{a}$ should be known). In the third step the remaining life ratio (the result of the second step) must be multiplied by the allowable repetition number on the overlaid pavement Eq. (2), with the knowledge of the horizontal tensile strain at the bottom of asphalt overlay and the existing asphalt stiffness modulus

\section{Current Hungarian Design Practice of Asphalt Over- lays}

In Hungary the current asphalt overlay design was developed on the basis of measured deflections of existing pavement and subgrade. The essential of this method is that the designer first determines the allowable deflection values depending on the design axel load repetition $(100 \mathrm{kN})$ for different homogenous subsections, Table 1

In the second step the designer uses a diagram, Figure 1 where the overlay thickness of the pavement depend on the measured (or characteristic) deflection $\left(s_{\mathrm{m}}\right)$ and allowable deflections (SE). The calculation of the characteristic deflection can be made according to Eq. (4)

$$
s_{m}=\bar{b}+\mu \cdot s_{b}
$$

Where $\bar{b}$ is the average of deflections, $s_{\mathrm{b}}$ is the standard deviation of deflections, $\mu$ is the factor of probability level, its values: $\mu=$ 1,64 or $\mu=1,28$ in depending on the traffic loading.

It can be seen in Figure 1 that the thickness of the overlay does not depend on the type of applied asphalt which is used for overlay However, this is not correct, because the different asphalt types have different mechanistic properties consequently this method does not provide the optimum solution. In the next part we will introduce another method which will consider the types of hot mix asphalt.

\section{Suggestion for a Mechanistic-empirical Method for Overlaying}

The basic principle of this method that the thickness of overlay must be determined by the mechanical properties of the existing and new asphalt overlay layers. Because in Hungary the roads, during their very long life the pavements became gradually thicker and their cross-sections became wider. This is 
Tab. 1. The allowable deflection functions ( $F_{100}$ is the designing axel load)

\begin{tabular}{cc}
\hline The type of the existing pavement & The deflection functions (SE, mm) \\
\hline Fullyflexible pavement & $S E=25.0 \times\left(F_{100}\right)^{\frac{-1}{4.00}}$ \\
\hline Asphalt concrete pavement & $S E=14.5 \times\left(F_{100}\right)^{\frac{-1}{4.55}}$ \\
\hline Semi-rigid pavement & $S E=9.0 \times\left(F_{100}\right)^{\frac{-1}{5.00}}$ \\
\hline
\end{tabular}

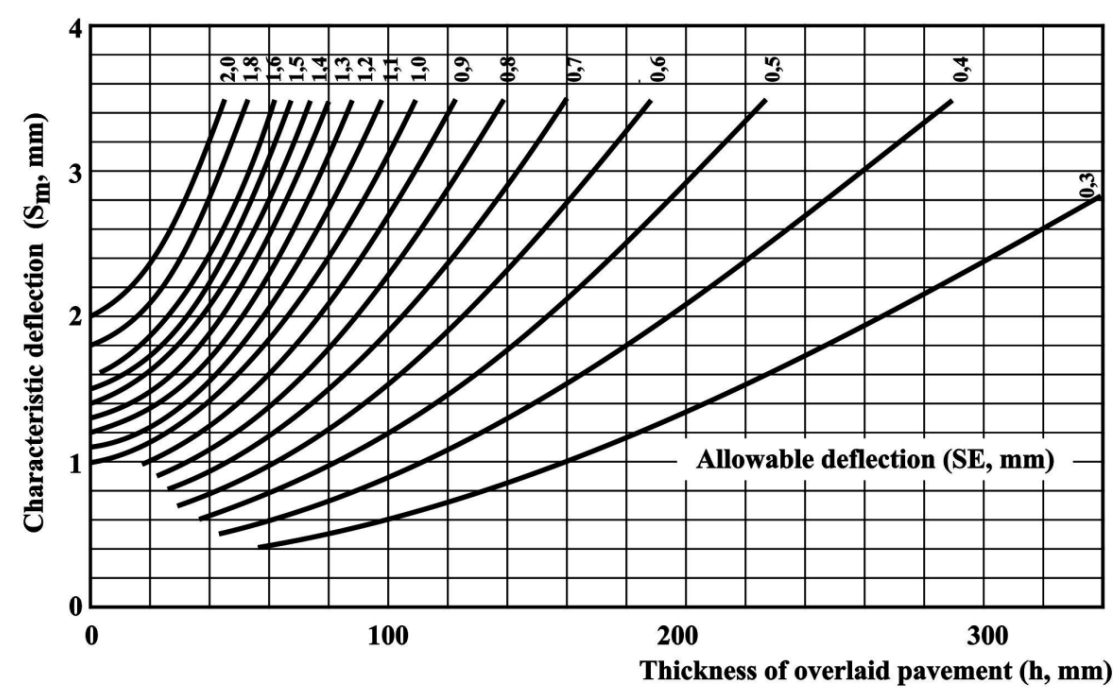

Fig. 1. Determination of the overlay thickness 8

the reason of the very wide range of materials of existing old pavement constructions. As a consequence of these, different kinds of existing layers have to be calculated instead of one single equivalent layer. The equivalent layer calculation is possible according to two ways. The quicker method is the use of a falling weight deflectometer equipment (FWD) which provides continuously the moduli values of the total road construction before overlay (therefore another calculation has to be made which considers the moduli of the non-existing layers). According to the second method, cylindrical specimens with large diameter $(320 \mathrm{~mm})$ have to be taken from the pavement. From these specimens about three trapezoid specimens for two points beam fatigue tester can be cut out by a precision saw-cut machine, and the moduli of hot mix materials of existing layers can be determined [9].

For the equivalent modulus calculation a method of Nemesdy [10, 11] is used; Nemesdy improved Odemark's [12] approximate solution for a two-layer system. The essential of this method is provided in the following section; the arrangement of the pavement model can be seen in Figure 2

If the upper layer (which is the overlay) is elastic, the $P$ contact pressure generates $y$ deflection. Between these the La Grange equation can be used:

$$
\begin{aligned}
& D \Delta^{2} y=D\left(\frac{d^{2} y}{d r^{2}}+\frac{1}{r} \frac{d y}{d r}\right)=P \\
& D=\frac{E F \times H F^{3}}{12-\left(1-M F^{2}\right)}
\end{aligned}
$$

Where, $D$ means the stiffness of the pavement material. After this calculation, the upper layer properties ( $E F$ modulus, $M F$
Poisson's ratio) are replaceable with one layer which has $E L$ modulus, $M L$ Poisson's ratio and $D$ stiffness.

$$
D=\frac{E F \times H F^{3}}{12-\left(1-M F^{2}\right)}=\frac{E L \times H L^{3}}{12-\left(1-M L^{2}\right)}
$$

The thickness of replacing layer $(H H)$ must be the following (in which $V=0,9$ is a correction factor).

$$
H H=V \times H F=\left(\frac{E F}{E L} \times \frac{1-E L^{2}}{1-E F^{2}}\right)^{1 / 3}
$$

If the equivalent modulus of replacing one layer is $G F$ and the Poisson's ratio is 0,5 , than $S$ deflection of the system can be calculated as follows:

$$
S=2\left(1-M^{2}\right) \frac{P \times R}{G F}=1,5 \frac{P \times R}{G F}
$$

The $S$ deflectionmust be equal to the original two layer's deflection (their moduli: $E F, E L$ ):

$$
S=S A+S F
$$

Using the following equations:

$$
\begin{gathered}
Z F=V \times H F \\
E=E F, \quad M=M F, \quad Z=Z F
\end{gathered}
$$

In this case $S F$, the deflection of upper layer should be the following:

$$
\begin{aligned}
S F= & \frac{P \times R}{E F} \times\left[2 \times\left(1-M F^{2}\right)-2 \times\left(1-M F^{2}\right) \times\left(1+\left(\frac{Z F}{R}\right)^{2}\right)^{\frac{1}{2}}\right. \\
& \left.+\frac{(1+M F) \times\left(\frac{Z F}{R}\right)^{2}}{\left[1+\left(\frac{Z F}{R}\right)^{2}\right]^{\frac{1}{2}}}-\left(M F+2 M F^{2}-1 \times\left(\frac{Z F}{R}\right)\right)\right]
\end{aligned}
$$




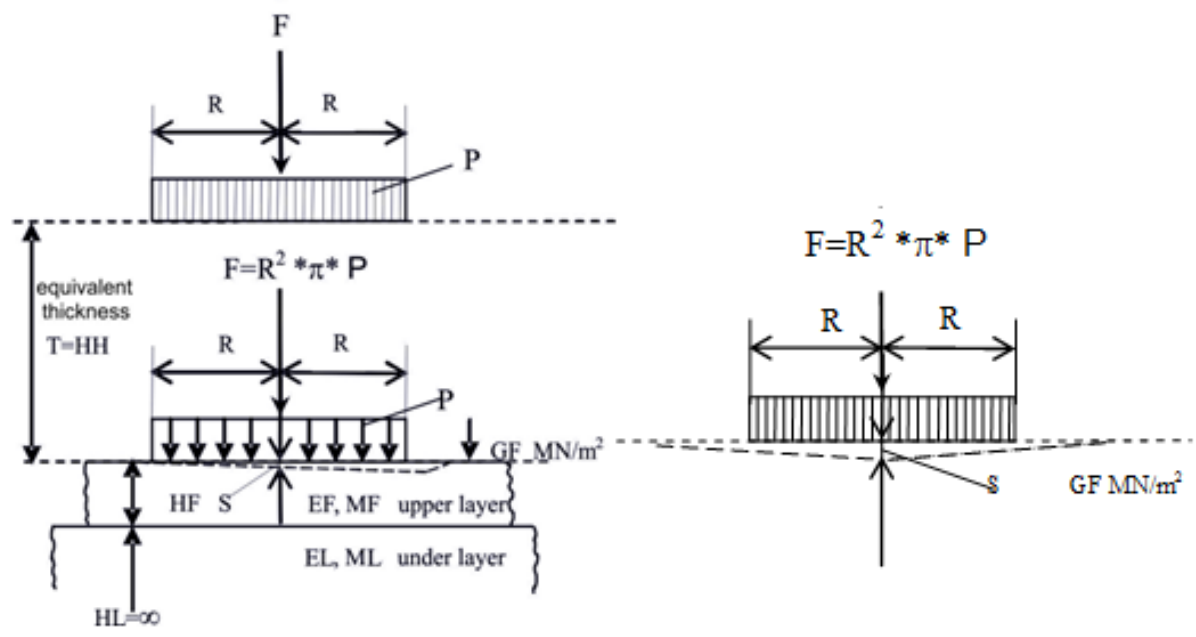

Fig. 2. Two-layer pavement structure loaded with a circular plate $[10]$

Using the following equations:

$$
\begin{gathered}
Z L=V \times H F=\left(\frac{E F}{E L} \times \frac{1-E L^{2}}{1-E F^{2}}\right)^{1 / 3} \\
E=E F, \quad M=M F, \quad Z=Z F
\end{gathered}
$$

The deflection of the lower layer:

$$
\begin{aligned}
S A & =\frac{P \times R}{E L} \times\left[2 \times\left(1-M L^{2}\right) \times\left(1+\left(\frac{Z L}{R}\right)^{2}\right)^{\frac{1}{2}}\right. \\
& \left.+\left(M L+2 M L^{2}-1\right) \times\left(\frac{Z L}{R}\right)-(1+M L) \times \frac{\left(\frac{Z L}{R}\right)^{2}}{\left[1+\left(\frac{Z L}{R}\right)^{2}\right]^{\frac{1}{2}}}\right]
\end{aligned}
$$

Using the above series of equations for a very often used case in Hungary, where different asphalt layers are on a rigid subbase and subgrade (with parameters: $R: 0,15 \mathrm{~m} ; M L: 0,45$; $M F: 0,25 ; M: 0,5 ; E F\left(E_{\text {subgrade }}\right): 40 \mathrm{MPa} ; E F\left(E_{\mathrm{Rb}}\right): 2000 \mathrm{MPa}$; $\left.H F: 0,15 \mathrm{~m} ; V: 0,9 ; F: 50000 \mathrm{~N} ; P: 707714 \mathrm{M} / \mathrm{mm}^{2}\right)$ can be calculated diagrams of Figure 3

The developed overlay calculation method uses the above showed procedure for the equivalent stiffness of existing pavement. But this example concern to the semi-rigid constructions, in practice there are more types of highway constructions. Without the mentioned semi-rigid construction there are two main groups of them. In Hungary several pavements were constructed with full depth asphalt and asphalt layers on granular subbase layer. The equivalent moduli of flexible pavement were determined similarly to the pavement with rigid subbase. Figure 4 shows the equivalent moduli of these pavements in function of thicknesses and moduli of existing asphalt layer. (Parameters of this calculation: $R: 0,15 \mathrm{~m} ; M L: 0,45 ; M F: 0,45 ; M: 0,5$; $E F\left(E_{\text {subgrade }}\right): 40 \mathrm{MPa} ; E F\left(E_{\mathrm{Rb}}\right): 135 \mathrm{MPa} ; H F: 0,20 \mathrm{~m} ; V: 0,9$; $F: 50000 \mathrm{~N} ; P: 707714 \mathrm{M} / \mathrm{mm}^{2}$ ). Comparing the two figures it can be seen that the equivalent moduli of flexible pavements are lower about $40 \%$ than the moduli of rigid subbase pavement.

For the calculation of the overlay thickness the equivalent stiffness and the thickness of existing layer, the type of subbase course and the allowable strain of undermost side of asphalt layer are needed. This strain value can be determined by a two point bending beam fatigue tester. This test result gives fatigue test curve, Figure 5. Because in the Eq. (2) the effect of $\varepsilon_{t}$ is bigger the following simplified form is usually used:

$$
N_{f}=c_{1} \cdot \varepsilon_{t}^{-f_{2}}
$$

From Eq. 15 the following form can be calculated for the allowable number of load repetition.

$$
\log c_{1}=\log N_{f}+f_{2} \cdot \log \varepsilon_{t}
$$

From the fatigue test the followings can be derived:

$$
\begin{gathered}
f_{2}=3,162 ; N_{\mathrm{f}}=1000 \text { and } \varepsilon_{\mathrm{t}}=11,9 \times 10^{-4} ; \\
\log c_{1}=\log 1000+3,162 \cdot \log 0,00119=-6,247, \text { or } \\
c_{1}=5,66 \times 10^{-7} .
\end{gathered}
$$

The fatigue equation reads then:

$$
N_{f}=5,66 \cdot 10^{-7} \cdot\left(\varepsilon_{t}\right)^{-3,162}
$$

The basis of overlay method is a pavement structure model consists of five layers and calculated using the Shell-BISAR software, Figure 6[13].

The model parameters are summarized in Table 2 .

First of all, it was examined what was the strain at the bottom of the existing layer after the removal of the original surface and binder course. Therefore a three-layer pavement model was created, which consisted of subgrade, subbase and existing layer. Three different thicknesses of subbase layer were applied 60, 120 and $180 \mathrm{~mm}$. Full slip was assumed between the subgrade and subbase and between the subbase and the lowest asphalt layer. The $120 \mathrm{~mm}$ and $180 \mathrm{~mm}$ layers were divided into 


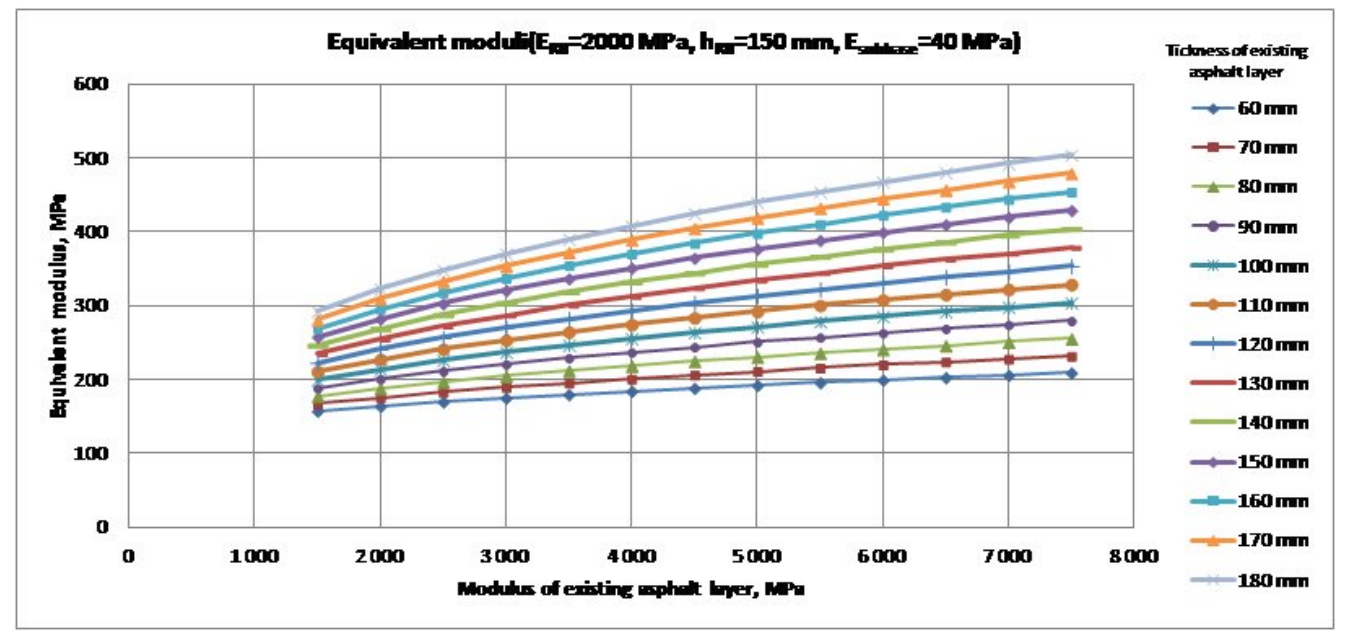

Fig. 3. Equivalent moduli when asphalt layers of different thicknesses are laid on a rigid subbase

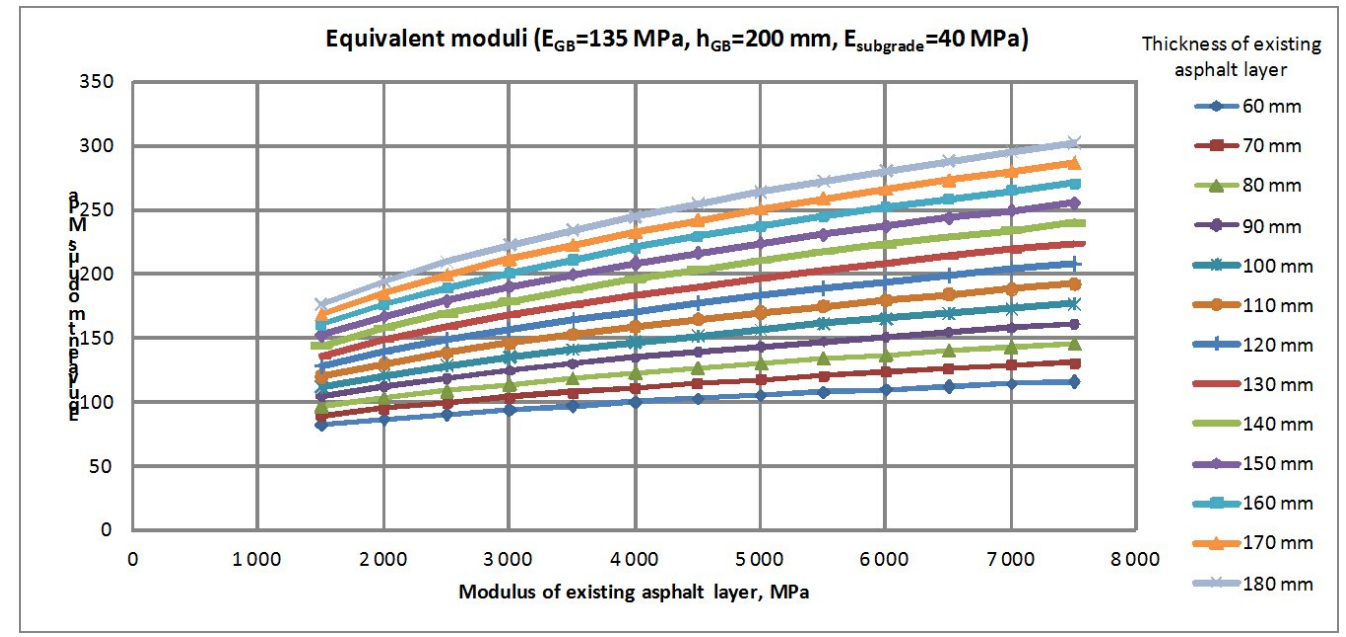

Fig. 4. Equivalent moduli when asphalt layers of different thicknesses are laid on a granular subbase

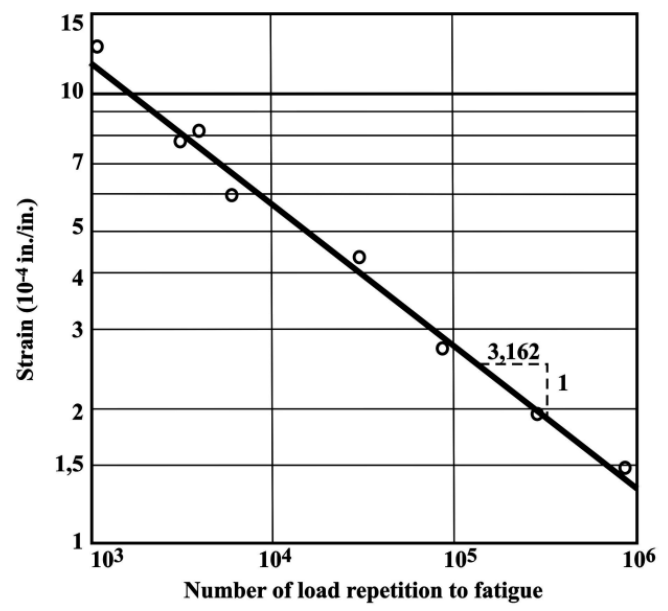

Fig. 5. The fatigue test result representation form

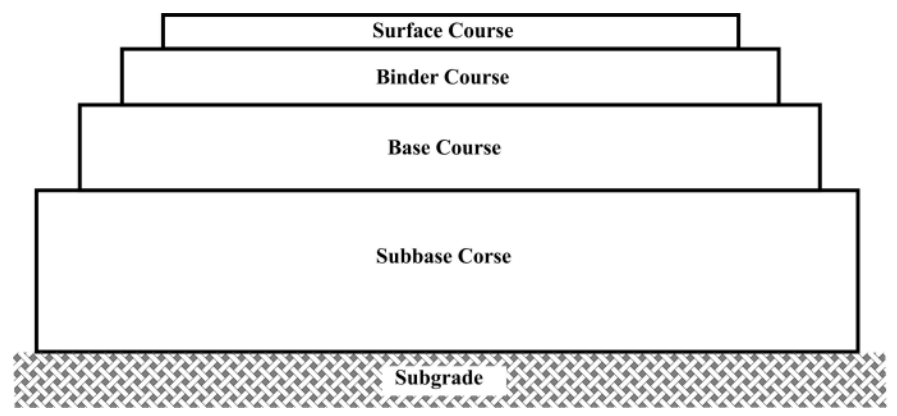

Fig. 6. A Shell-BISAR model for asphalt overlay 
Tab. 2. The overlay model parameters

\begin{tabular}{cccc}
\hline Layer types & Thickness, mm & Stiffness MPa & Poisson's ratio \\
\hline Surface course & 40 & 3500 & 0.35 \\
\hline Binder course & $70 \ldots 240^{*}$ & $4000 \ldots 10000^{*}$ & 0.35 \\
\hline Existing layers & $60 \ldots 180^{*}$ & $1500 \ldots 7500^{*}$ & 0.35 \\
\hline Granular subbase $(F Z K A)$ & 200 & 135 & 0.25 \\
\hline Rigid subbase $\left(C_{\mathrm{kt}}\right)$ & 200 & 2000 & 0.25 \\
\hline Rigid subbase $\left(C_{\mathrm{kt}}\right)$ & 150 & 2000 & 0.25 \\
\hline Subgrade & & 40 & 0.45
\end{tabular}

*varying values

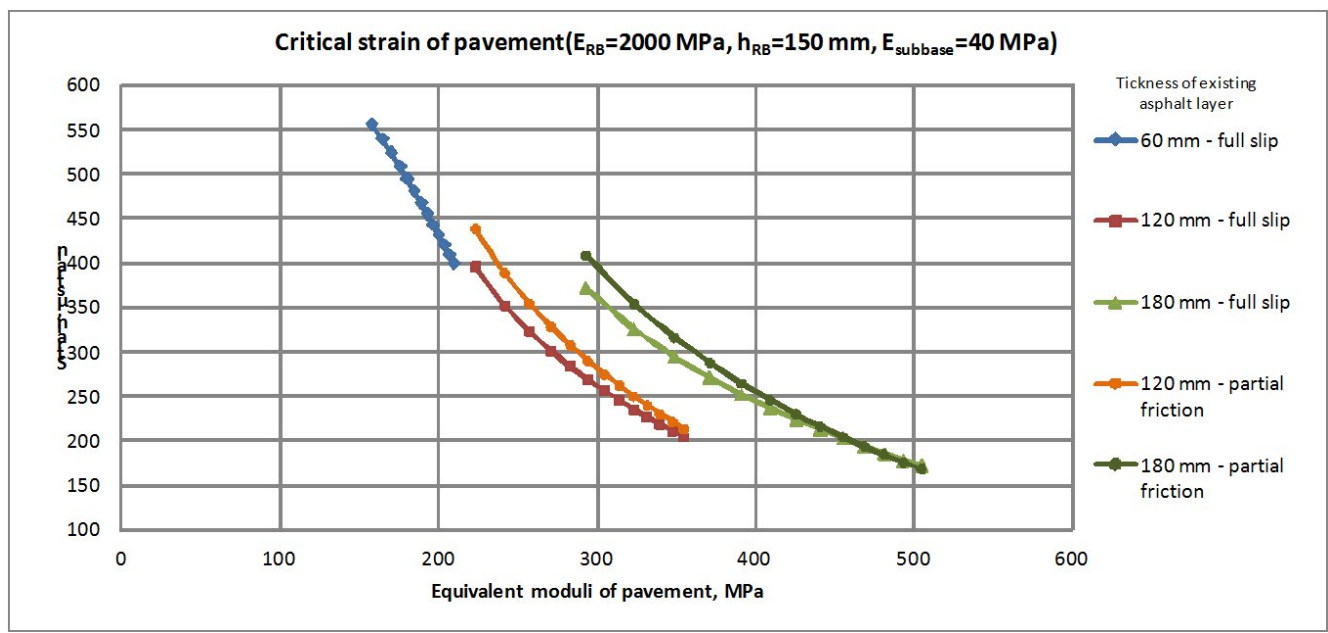

Fig. 7. Strain of semi-rigid pavement based on Shell BISAR model

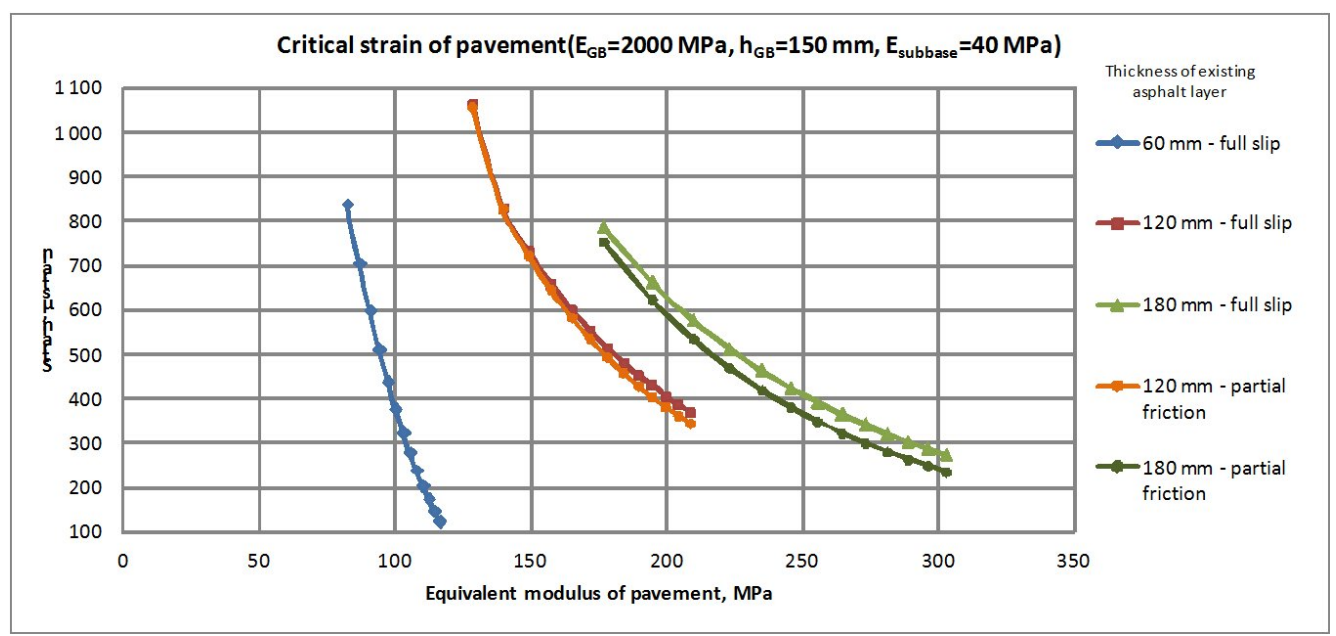

Fig. 8. Strain of flexible pavement based on Shell BISAR model

Tab. 3. The parameters for an overlaying method

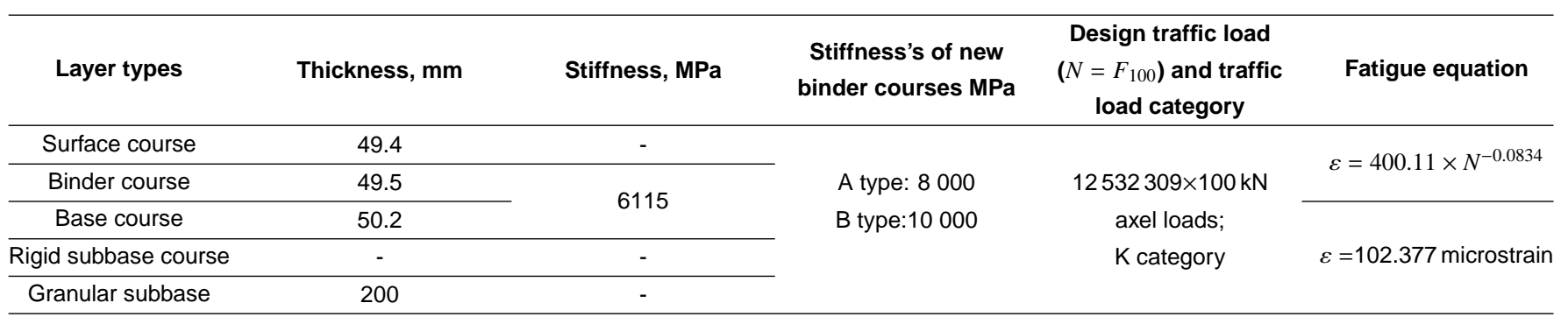




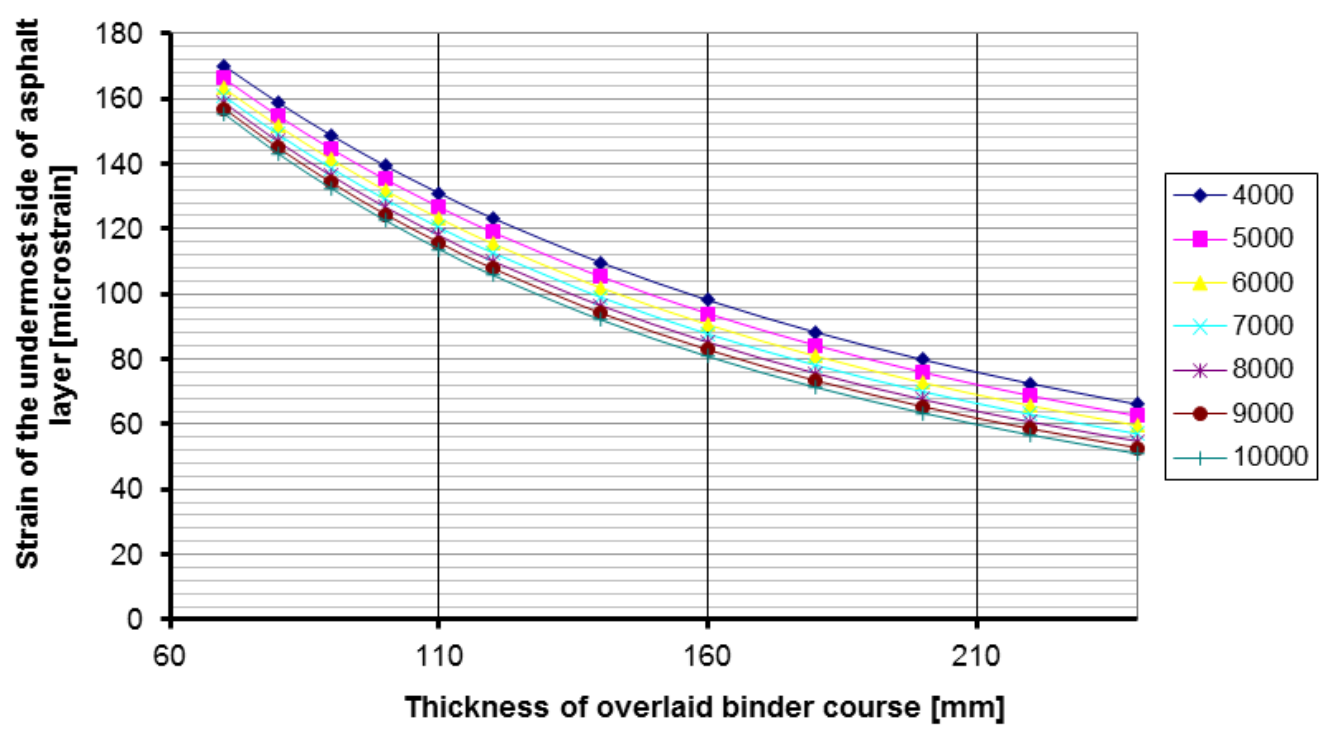

Fig. 9. The thickness of overlaid binder course (existing asphalt thickness: $100 \mathrm{~mm}$, existing asphalt stiffness: $6500 \mathrm{kN}$, granular subbase: $200 \mathrm{~mm}$ )

$2 \times 60 \mathrm{~mm}$ and $3 \times 60 \mathrm{~mm}$ sub-layers. The calculations were carried out in two ways. In one case full slip was set between the asphalt layers. In the other case partial friction was presumed.

The BISAR software offers the opportunity of full and partial friction or full slip between the layers. The classical friction coefficient cannot be set. The friction can set by the Shear Spring Compliance parameter or Reduced Spring Compliance (RSC). The value of this parameter depends on the radius of the loading plate, the Poisson-ratio and the elastic modulus of layer over bounder surface. In the course of calculations the $R S C=15 \mathrm{~m}$ was set, if the layers slip on each other, and $R S C=1,5 \mathrm{~m}$, if it was partial slip between layers. Because it is an existing and ready to be overlaid pavement structure, therefore it is not necessary to take into account the full friction between layers. Figure 7 shows the results of semi-rigid pavement and Figure 8 shows the results of flexible pavement.

From the above figures it can be concluded that the critical strains of existing pavements exceed the allowed strain values significantly. This explains the necessity of overlaying. The following it can be read the one way of the overlay design with analytical approach. The calculations carried out based on a fivelayer pavement model (surface layer, binder layer, existing layer, subbase, subgrade), which is shown in Figure 6. The models were prepared with 3 different subbase layers ( $200 \mathrm{~mm}$ granular subbase, 150 or $200 \mathrm{~mm}$ rigid subbase) according to the Hungarian catalogue pavement design system. The thicknesses and stiffness of the existing asphalt layer and the binder layer varies as summarized in Table 2. Thereafter the requirements of different characteristics pavement structures were determined. The result of model calculation is a range of curves depending on stiffness and thickness of existing pavement layers and subbase layers. From these curves the thicknesses of the strengthening binder course can be determined.

The application of the above method can be studied in the fol- lowing example; the parameters of an existing semi-rigid pavement are given it, Table 3

One of the tables of overlaying method can be seen in Figure 9 By using this diagram the thickness of the binder course can be estimated, which depend on the undermost side strain of the existing layer and stiffness modulus of new binder course.

According to Figure 9 the thickness of the new binder course would be $130 \mathrm{~mm}$ for type A and $120 \mathrm{~mm}$ for type B.

To compare the earlier method, the measured characteristic deflection of the original pavement construction was $1,2 \mathrm{~mm}$ and the allowable deflection: $0,40 \mathrm{~mm}$. The required strengthening thickness would result $130 \mathrm{~mm}$.

\section{Conclusions}

This paper deals with theory of asphalt overlay design. Addition to the general overlay design methods, the current Hungarian asphalt overlay practice was also presented. The aim of this article is the description of a mechanical-empirical design method, which was developed at Department of Highway and Railway Engineering of BME. In the course of modeling on the basis of the strain, which can be calculated at the bottom of the asphalt layer of a five-layer pavement structure, the necessary thickness of overlaying binder course can be determined. In order to simplify the calculations, the equivalent modulus was used instead of the moduli of existing asphalt layers. The outcome of this research work is the asphalt the overlay design curves, which can be readily used in for pavement overlay design purposes. The design method was illustrated in an example.

\section{Acknowledgement}

The work reported in the paper was developed in the framework of the project "Talent care and cultivation in the scientific workshops of BME" project. This project is supported by the scheme TÁMOP-4.2.2.B-10/1-2010-0009. 


\section{References}

1 Theyse HL, De Beer M, Rust FC, Overview of South African Mechanistic Pavement Design-method, Journal of the Transportation Research Board, 1539, (1996), 6-17, DOI 10.3141/1539-02

2 Tóth C, Analysis of the quality variances of asphalt production by Monte Carlo Simulation, Periodica Polytechnica Civil Engineering, 54(1), (2010), 67-72, DOI 10.3311/pp.ci.2010-1.08

3 Lundstorm R, Ekblad J, Isacsson U, Karlsson R, Fatigue Modeling as related to flexible pavement design, Road Materials and Pavement Design, 8(2), (2007), 165-205, DOI 10.3166/rmpd.8.165-205

4 Aravind K, Animesh D, Pavement design with central plant hot-mix recycled asphalt mixes, Construction and Building Materials, 21, (2007), 928936, DOI 10.1016/j.conbuildmat.2006.05.004

5 Hernández-Olivares $\mathbf{F}$, Barluenga $\mathbf{G}$, Parga-Landa $\mathbf{B}$, Bollati $\mathbf{M}$, Witoszek B, Fatigue of recycled tyre rubber-filled concrete and its implications in the design of rigid pavements, Construction and Building Materials, 21, (2007), 1918-1927, DOI 10.1016/j.conbuildmat.2006.06.030

6 El-Maaty Behiry AEA, Fatigue and rutting lives in flexible pavement, Ain Shams Engineering Journal, 3, (2012), 367-374, DOI 10.1016/j.asej.2012.04.008

7 Asphalt Overlays for Highway and Street Rehabilitation, Manual Series No. 17, Asphalt Institute, 1983.

8 ÚME 2-1.202. Overlay design of asphalt pavements, The Hungarian Road Society, 2005. in Hungarian.

9 Pethő L, Tóth C, Long-term pavement performance evaluation, In: Korsunsky AM (ed.), 7th RILEM International Conference on Cracking in Pavements, RILEM Bookseries 4, 2012, pp. 267-276, DOI 10.1007/978-94-0074566-7_26

10 Nemesdy E, Calculation of the deflection and strains in multi-layers pavement structures, Review of Transportation Sciences, 5, (1986), 193-201. in Hungarian.

11 Nemesdy E, Overlay design with deflection measured according to mechanistic principle, Review of Civil Engineering Science, 10, (1986), 408-420. in Hungarian.

12 Odemark N, Investigations as to the Elastic Properties of Soils and Design of Pavements According to the Theory of Elasticity, Statens Vaginstitut, Stockholm, Sweden, 1949.

13 Fi I, Bocz P, Pethö L, Tóth C, Design of pavement structures, In:, Terc, 2012, pp. 259-364. in Hungarian. 